Professora titular da PUC-SP na Pós-Graduação em Comunicação e Semiótica. Codirigente do Centro de Pesquisas Sociossemióticas (CPS). Publicou uma dezena de artigos sobre a inter-relação entre comunicação e moda. Seu livro mais recente é Linguagens na comunicação: desenvolvimentos de semiótica sincrética (Estação das Letras/CPS, 2009), organizado em parceria com Lucia Teixeira.

E-mail: anaclaudiamei@hotmail.com

\title{
No arrasto das sandálias: reinvenções de um modo de vidă II
}

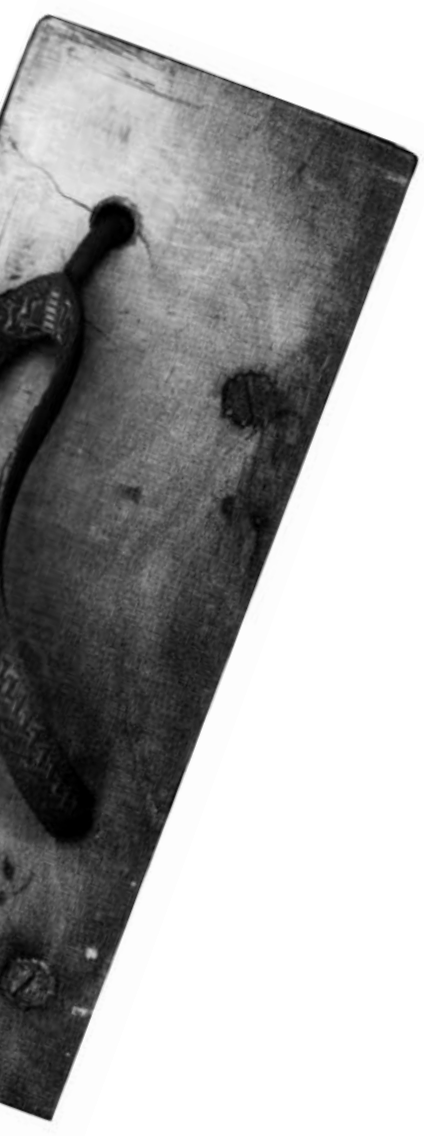

Facteur Celeste ${ }^{1}$ tornou-se uma das mais destacadas butiques de comercialização de sandálias no mundo em suas duas recentes décadas de vida. Do Japão, uma de suas proprietárias trouxe, em 1994, uma sandália zori ${ }^{2}$ que passou a ser fabricada nos formatos de cada um dos pés e com a numeração característica dos calçados ocidentais, deixando então no seu translado do Extremo Oriente à Europa de ser ambidestra e de tamanho único.

De fato, as rasteirinhas abandonaram de vez as classes populares e os usos tradicionais do calçado ligado às culturas orientais e tornaram-se artigos de luxo no Ocidente, onde as sandálias de marcas como Chanel, Louis Vuitton, Manolo Blahnik, Prada, entre outras, atingem preços de ouro. No entanto, podemos dizer que os diversos modelos e propostas não apresentam variações significantes da estruturação original do calçado, e o que faz a diferença e distinção entre as sandálias é justamente o conceito de marca.

\section{Dinâmicas dos sentidos}

No aguçamento do olhar entre o modelo de sandálias $\mathrm{Ha}-$ vaianas e o da Facteur Celeste, e se entre essas incluíssemos a sandália zori, a fisherman ${ }^{3}$, descalçamos uma operação de intertextualidade em que o enunciador da tradição não é escondido por este de nosso tempo da sociedade de consumo, mas, ao contrário, ambas as enunciações são postas em dialogia. 0 analista do calçado da moda é forçado a tratar essas operações e relações não mais simplesmente como cópia, roubo, mas como operações tradutórias que ligam culturas e axiologias em um multiculturalismo tão característico do contemporâneo.

Os papéis temáticos das sandálias estão relacionados às atividades laborativas, mas estas características se distanciam dessas novas propostas. 0 uso elitizado desse calçado confere status social ao usuário ao receber uma valorização simbólica então apoiada no conceitual da marca, no preço, na distribuição e nos pontos de venda da comercialização onde esses atributos passam a ser incorporados ao produto e conferem distinção. Desmontada a democratização do uso, a sandália passa, de novo, a ser um artifício qualificante dos modos de vestir o corpo. 0 seu 
uso é operador de uma marca significante que destaca a condição social e o grupo de pertencimento seleto do usuário. A aura das marcas de luxo reveste os pés e os passos das celebridades.

0 parecer do privado é transformado na qualificação figurativa de um modo de vida e, particularmente, de um modo de levar e sentir o viver com deleite. Sob as luzes mediáticas para 0 ser visto, o modo de estar do privado é invertido e passa a ser um modo de presença do público. Desnudada de sua simplicidade e praticidade conferidas por sua dimensão plástica e figurativa, a visualidade da sandália propaga um modo de presença estereotipada que tem seu lugar em nosso social. A dimensão plástica da sandália está associada à dimensão sensivel que produz o "fazer sentir" estésico tanto da liberdade dos pés, da pele ao vento e do despojamento, quanto da beleza com o sentir sensorial da carne encarnada do corpo na sandália. 0 sentir sensorial do portá-la no social segue também propósitos do "fazer fazer" da ordem da manipulação do destinador social da indústria da moda. Entre a ordem sensivel e a ordem manipulatória, o regime de ajustamento e o de manipulação estão hierarquizados na dinâmica dos sentidos pelo regime da programação de modo de ser corporais e comportamentais que estão prescritos pelo papel temático do arrastar as sandálias na atualidade, enquanto não deixa de figurativizar uma sempre renovada liberdade que exala.

\section{Simultaneidade cultural e intertextualidade}

No arrasto das solas de couro, palha, junco, plástico ou no claque-claque dos solados de madeira ou metal, observase toda uma sonoridade proveniente de outras culturas que se inscrevem em nossa contemporaneidade nas formas de vestir os pés com as sandálias. Os modos de vida ocidentais vão assim sendo permeados pelos de outros povos e outras tradições que não são neutralizados, mas se manifestam, presentificam-se, saindo do adormecimento encantatório. As ambiências de trabalho e de festas aproximam-se da descontração do lazer, do esporte, do descanso e, em todos os cantos dos espaços públicos, nota-se uma intimidade característica dos espaços do privado rompendo as especificações de barreiras demarcatórias de uma separação espacial, temporal, actorial. Um clima de sentir-se à vontade independente das situações tem assim repercutido na imensidade unificada do planeta cada vez mais indiferenciado em suas localidades e fazeres.

Anunciadora de outros costumes junto aos nossos, essa sonoridade carrega ainda uma marcada presença do outro que entra em nossas feições, aparências, estilos, amenizando as distâncias e as diferenças do particular e do global. Entre o modelo de sandália de Ferragano com solado de alumínio e tiras de couro em mais uma reinvenção da tradição que é estampada

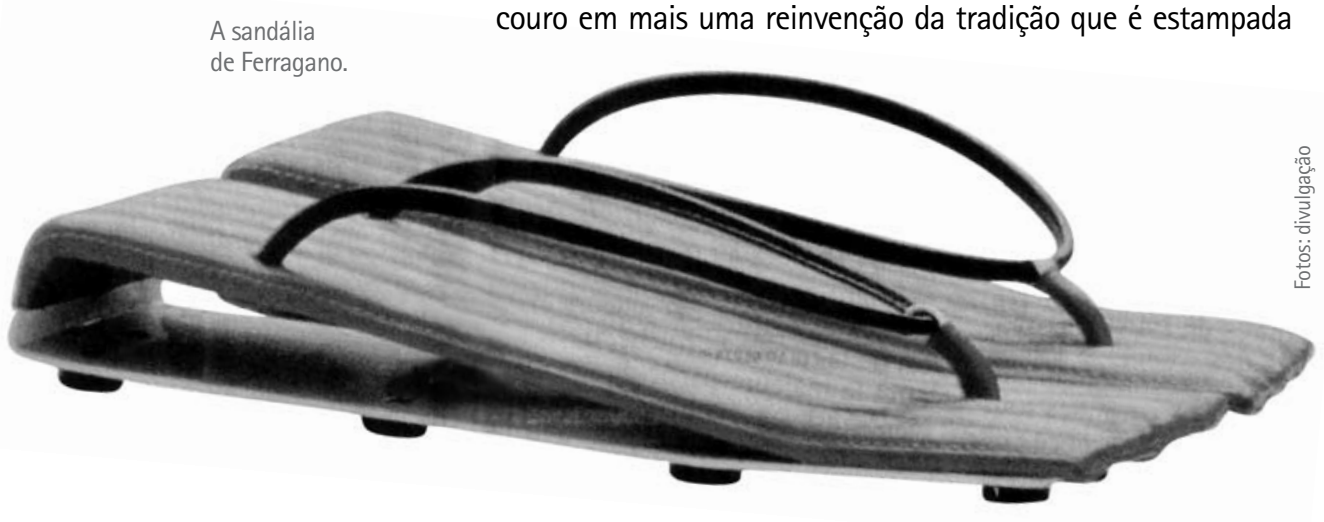


dialogicamente, em oposição à geta criada por Alan Scherk, percebemos que o choque dos materiais nos põe corpo a corpo com o multiculturalismo de nossa sociedade, que nos posiciona "aqui" e também "lá" e, mais além, em um "alhures" que consideramos nosso trabalho demarcar e analisar.

Em uma duração milenar na atualidade vivificada somos convidados à constatação de como somos todos em todas as épocas uma só totalidade "pé". Com uma criação para os eventos do centenário da imigração japonesa ao Brasil, em 2008, Alan Scherk modela em sua sandália a dialogia entre usos e costumes.

$\mathrm{Na}$ retangularidade dos distintos suportes matéricos o solado de madeira de Scherk, com as tiras de plástico das Havaianas, e o solado de metal de Ferragano, com as tiras de couro também milenar nas suas origens e empregos - e nos modos de articulações dos materiais das sandálias visualizamos o multiculturalismo impregnando as culturas. A sandália e seu uso propõem novos objetos para nosso estudo de quem somos e o que presentificamos nos claques-claques ou nos arrastos de nossos pés no mundo.

Das areias do Egito, das raizes africanas que nos inundam, do Oriente Extremo às terras brasileiras há uma continuada série de reinvenções de modos de vida marcando o nosso jeito de ser e levar a vida. A moda das sandálias nos pés em voga só nos faz ver o que essa indústria da novidade eterna não consegue mais encobrir: o jogo de poder das culturas travado entre Oriente e Ocidente e entre as partes dessas totalidades.

\section{NOTAS}

${ }^{[1]}$ Para saber mais, acesse: <http://facteurceleste.cesura.net>.

${ }^{[2]}$ A sandália zori caracteriza-se pelo solado de palha de arroz tecida ou madeira lascada no qual se fixavam as fitas tecidas e retorcidas reforçadas.

${ }^{[3]}$ Sandália de plástico dos pescadores da Riviera Francesa que protegia os pés desses trabalhadores em sua atividade pelas superficies rochosas da orla mediterrânea.

${ }^{[4]}$ De origem japonesa, a geta é talhada ambidestra e de tamanho único e tem as tiras atadas ao solado de madeira.

\section{BIBLIOGRAFIA}

GREINER, C.; FERNANDES, R. M. (Org.). Tokyogaqui: um Japão imaginado. São Paulo: SESC SP, 2008.

LANDOWSKI, E. Les interations riquées. Limoges: Pulim, 2005.

Passions sans nom. Paris: PUF, 2004.

. Presenças do outro: ensaios de sociossemiótica. São Paulo: Perspectiva, 2002.

OLIVEIRA, A. C. de. A plástica sensivel da expressão sincrética e enunciação global. In: TEIXEIRA, L. (Org.). Linguagens na comunicação: desenvolvimentos de semiótica sincrética. São Paulo: Estação das Letras e Cores/CPS, 2009, p. 79-140 